\title{
Contextualização da matemática financeira com noções de mercado financeiro: uma proposta de ensino crítico e ativo no ensino médio
}

\section{RESUMO}

O ensino da Matemática Financeira no ensino médio representa uma grande oportunidade de utilizar a disciplina de Matemática de maneira menos expositiva e com maior atitude crítica e reflexiva dos alunos, podendo construir conhecimentos úteis para o exercício de sua cidadania. Neste trabalho, a proposta de ensino crítico a partir da resolução de problemas é complementada com a aplicação dos conhecimentos de juros simples e compostos ao entendimento das aplicações de Renda Fixa e Variável, além das demonstrações práticas do uso dos sistemas de amortização Price e SAC. Dessa forma, baseando-se também em diferentes referenciais a respeito do tema, pode-se perceber que, além de atuar como instrumento de contextualização para diversas situações do cotidiano, a Matemática Financeira pode ser uma ferramenta transformadora mediante a experiência dos alunos nas aulas de atemática. A pesquisa realizada está ancorada em análises de artigos que relatam aulas em que se adotou o método da Aprendizagem Baseada na Resolução de Problemas (ABRP), o qual pode estimular o raciocínio e a intuição dos alunos, e elaborar uma proposta de aula que assimile os pontos fortes relatados, para depois, submeter essa proposta à avaliação de professores de Matemática. Como resultados, percebeu-se que a maioria dos professores que participaram da avaliação aprovou a proposta de aula sugerida neste trabalho, mas muitos deles consideraram difícil implementar a ideia e convencer os alunos da importância do tema. Por fim, notou-se que as aulas sugeridas devem ser adaptadas às capacidades avaliadas dos alunos e seu interesse em aprender um conteúdo extra e que exige maior participação.

PALAVRAS-CHAVE: Matemática Financeira. ABRP. Mercado Financeiro. 


\section{INTRODUÇÃO}

Este trabalho parte do princípio de que a função do ensino médio não se limita a preparar os alunos para ingressar no ensino superior, pois também inclui o desenvolvimento da capacidade dos estudantes de refletir sobre sua realidade, para criar a partir dela e interagir de maneira construtiva com os outros cidadãos. Para esse fim, o ensino da Matemática, da forma mecânica que é ensinado atualmente, acaba parecendo, muitas vezes, inadequado, conforme será exposto nos estudos de caso presentes na revisão de literatura.

Como meio de mudar esse diagnóstico, o ensino mais contextualizado da Matemática Financeira é uma possibilidade de grande potencial, pois os alunos chegam ao Ensino Médio familiarizados com algumas ideias relacionadas a dinheiro, gastar, poupar, investir e, principalmente, de que existem juros. No entanto, eles aprendem juros simples no Ensino Fundamental e juros compostos ao longo do Ensino Médio, sem avançar para a aplicabilidade desses conceitos.

Para abordar esse problema e como enfrentá-lo, é feito, neste trabalho, um breve exame das menções aos conceitos de Matemática Financeira na Base Nacional Comum Curricular (BNCC) do Ensino Médio e uma explicitação da metodologia que visa alterar esse foco, a saber, a resolução de problemas, que é a adotada nos modelos de aulas propostos nesta pesquisa.

\section{IDENTIFICAÇÃO DO PROBLEMA}

Neste tópico, é analisado o documento referente à Base Nacional Comum Curricular (BNCC), atualizada em 2018, para o ensino de Matemática no Ensino Médio. Em particular, será analisada a abordagem da Matemática Financeira no quadro de habilidades disponibilizado no documento em questão.

No quadro de habilidades da BNCC, os termos "Matemática Financeira" e "juros" aparecem com os seguintes objetivos:

a) resolver e elaborar problemas com funções logarítmicas nos quais é necessário compreender e interpretar a variação das grandezas envolvidas, em contextos como os de abalos sísmicos, pH, radioatividade, Matemática Financeira, entre outros. (MINISTÉRIO DA EDUCAÇÃO, 2018b);

b) investigar pontos de máximo ou de mínimo de funções quadráticas em contextos da Matemática Financeira ou da Cinemática, entre outros. (MINISTÉRIO DA EDUCAÇÃO, 2018b);

c) planejar e executar ações envolvendo a criação e a utilização de aplicativos, jogos (digitais ou não), planilhas para o controle de orçamento familiar, simuladores de cálculos de juros compostos, dentre outros, para aplicar conceitos matemáticos e tomar decisões. (MINISTÉRIO DA EDUCAÇÃO, 2018b);

d) resolver e elaborar problemas envolvendo porcentagens em diversos contextos e sobre juros compostos, destacando o crescimento exponencial. (MINISTÉRIO DA EDUCAÇÃO, 2018b). 
Nesses trechos, observa-se que a ideia de Matemática Financeira aparece como uma ilustração para o entendimento da importância prática de assuntos como funções exponenciais, logarítmicas e quadráticas. Uma possível interpretação para quem lê esse documento é que esses assuntos são fins em si mesmos, em vez de meios para se entender a Matemática Financeira, ou seja, esta tem o papel de ajudar a entender aqueles, mas não o contrário.

No caso dos juros, são citados problemas concretos, como controle de orçamento, destacando-se a capacidade de tomar decisões. Para complementar essa abordagem, o aluno poderia entender que o juro, na definição de Mises (2004), é a manifestação do fenômeno da preferência temporal, uma categoria inerente a toda ação humana.

Nesse sentido, deve ficar claro, para eles, que todos os bens, inclusive o dinheiro, são mais valorizados no presente do que no futuro e que, por isso, um empréstimo ou financiamento tem um pagamento sempre maior ao valor tomado ou que seria pago à vista.

No entanto, chama também a atenção o fato de, na BNCC, não aparecer a palavra "economia". Na definição de Robbins (1932), a economia, entendida como ciência econômica, é o estudo da escolha dos homens diante da escassez de recursos para atender aos fins que consideram mais urgentes. Ao partir do entendimento desse conceito, o aluno do Ensino Médio já pode refletir sobre a ideia de economia e Ciência Econômica como algo que não está distante da realidade do cidadão comum, pois todos agem diariamente para combinar os recursos disponíveis da melhor maneira para atender aos seus fins particulares considerados mais urgentes.

\section{METODOLOGIA}

Para explicar o método de ensino baseado na resolução de problemas, recorre-se a Dutch (1996). Segundo esse autor, ao contrário do que ocorre no ensino tradicional, em que se expõe os conceitos para, então, aplicá-los a um problema, a Aprendizagem Baseada na Resolução de Problemas (ABRP) parte de uma questão qualitativa aberta para explorar a intuição dos alunos e, só depois, elaborar o conceito referente à resolução encontrada.

No caso da Matemática Financeira, esse método pode ser mais vantajoso porque, ao contrário da maioria dos conceitos aprendidos em Matemática, os alunos conseguem traçar mais facilmente, paralelos entre a realidade em que vivem e o que está sendo apresentado nos problemas, o que não dispensa a posterior esquematização conceitual e expositiva.

Nesse sentido, Margetson (1991) acrescenta que a ABRP proporciona aos alunos a habilidade de integrar diferentes conhecimentos e reconhecer que estes não são dados a priori, mas sim identificados em cada problema, que pode aparecer em mais de uma disciplina. Para Margetson (1991), esse tipo de aprendizagem permite que se desenvolva uma maior capacidade de reflexão e espírito crítico, consolidando uma aprendizagem ativa, reduzindo, de certa forma, o alto controle do professor sobre o aluno. 
A partir disso, é possível concluir que a implantação da ABRP pode ser um choque para a visão de ensino unidirecional, em que o professor é visto como detentor do conhecimento e os alunos como assimiladores passivos. Em contraste, a ABRP parte do princípio de que os alunos já detêm conhecimentos importantes para sua aprendizagem e que, em diversas ocasiões, o papel do professor será instigar e mediar o uso desse conhecimento.

\section{Projeto Cálculo: uma abordagem crítica e ativa}

Na pesquisa de Almeida (2004), verifica-se uma proposta de ensinar Matemática Financeira em uma turma de ensino médio de uma escola que não se propunha a incluir esse assunto no currículo. $\mathrm{O}$ objetivo do projeto era, além da transmissão do conhecimento específico em si, construir um modelo de aprendizado ativo e crítico com os alunos, analisando as relações professor-aluno e aluno-aluno.

Segundo Almeida (2004), essa proposta de ensino com maior participação dos alunos, considerada "rompedora" pela pesquisadora, gerou um estranhamento inicial nos próprios alunos, que ficaram confusos sobre suas funções na sala de aula. Posteriormente, os alunos passariam a demonstrar maior interesse, inclusive batizando a experiência de "Projeto Cálculo".

Diante disso, a pesquisadora optou por trabalhar com grupos de cinco ou seis alunos. O objetivo era que cada grupo discutisse a resolução das questões e que um dos componentes, sorteados pela professora e pela pesquisadora, fosse ao quadro explicar a resolução. Assim, os alunos receberam reportagens para ler e discutir diversos assuntos, foi orientado que se atentassem aos valores percentuais e os compreendessem dentro de cada contexto.

Para Almeida (2004), além de saber calcular um desconto, os alunos devem entender o que é um desconto, refletir sobre o que seria um abuso de poder econômico em situações como cálculo de juros de dívidas e de alíquotas de impostos, o que a pesquisadora chama de "postura crítica".

Como conclusão sobre o Projeto Cálculo, Almeida (2004) afirma que sua proposta pedagógica foi uma boa fonte de reflexões já que apontou maneiras de superar a rigidez das normas disciplinares, em busca do que ela entende como os "reais objetivos pedagógicos da escola e da relação ensino-aprendizagem".

Para Almeida (2004), a preocupação com o tempo de aula e com as notas dos alunos, tanto em avaliações internas quanto em externas, como o ENEM, leva os professores a adotarem, ainda que não queiram, posturas autoritárias na sala de aula, como a própria pesquisadora se percebeu em alguns momentos do projeto.

A partir das conclusões da pesquisadora, é possível entender que o ensino da Matemática Financeira, além de ser importante em si para o desenvolvimento intelectual dos alunos e para o exercício efetivo de sua cidadania, é um meio com grande potencial de transformar as relações tradicionais de sala de aula e instigar os alunos a serem mais ativos na construção de seu conhecimento. Do mesmo modo, vale para o professor a reflexão sobre o potencial de uma organização de aula que fuja da mera exposição e correção de erros de exercícios. 


\section{Pesquisa-Ação: a co-construção do conhecimento}

Em sua pesquisa, Herminio (2008) analisa o conteúdo e a maneira com que os livros didáticos abordam o ensino da Matemática Financeira no Ensino Médio. Diferentemente da pesquisa de Almeida (2004), a de Herminio (2008) não se limitou a avaliar os alunos e a si mesmo, pois também investigou professores, diretores e pais de alunos.

Segundo Herminio (2008), a Pesquisa-Ação é um método de pesquisa que não se limita à ação ou à participação, mas também produz conhecimentos e faz com que o sujeito da pesquisa adquira experiência, de modo a contribuir com o debate sobre o objeto investigado. Em sua pesquisa de campo, nas salas de aula, Herminio (2008) decidiu dividir os alunos em grupos para resolver uma atividade, etapa em que o papel do professor é o de um observador, ou seja, ele apenas verifica, sem intervir, o comportamento de cada participante nos grupos.

Apenas em um segundo momento, continua Herminio (2008), o professor passa a ouvir as dúvidas dos alunos, mas sem dar as respostas, provendo apenas sugestões ou "dicas", até que, terminado o tempo de resolução, os grupos entregam seus trabalhos e os representantes de cada um deles vão até o quadro apresentar o que foi resolvido em grupo.

Em seguida, ressalta Herminio (2008), ocorre um momento em que a responsabilidade é essencialmente do professor, que é a formalização da nova teoria construída a partir do problema. Finalmente, conclui Herminio (2008), são deixadas tarefas para casa, que deverão ser entregues pelos alunos no início da aula seguinte, para serem discutidas pelo professor.

A partir dessa percepção, para ter uma visão mais geral do que pensam os alunos, Herminio (2008) entregou um questionário para estudantes de Ensino Médio de diversas escolas públicas e particulares. A maioria das respostas convergiu para os seguintes argumentos: "não gosto de estudar, mas isso é importante para ter um futuro melhor"; "a Matemática Financeira está presente no dia a dia dos indivíduos na sociedade"; "o professor não usa metodologias diferentes, a não ser o computador, às vezes"; e "não participo muito das aulas porque professor não dá abertura".

Além de aos alunos, Herminio (2008) também aplicou questionários a pais de alunos, professores e diretores. No caso dos pais, as respostas mais comuns envolveram o reconhecimento: da necessidade de apoiar os filhos e conferir seu desempenho e aplicação; da necessidade de participar da vida do filho na escola, embora muitos não consigam fazê-lo tanto quanto gostariam, por falta de tempo; da presença dos conceitos de Matemática Financeira no dia a dia das pessoas, como uma ferramenta utilitária para questões da vida comercial; e do papel desse assunto na educação financeira dos filhos, ensinando a poupar e a gastar com consciência.

Nas respostas dos professores de Matemática, houve muita convergência no reconhecimento do papel do professor na formação dos alunos, com destaque negativo às condições de trabalho que muitos profissionais encaram. Ao serem perguntados sobre a possibilidade de estimularem a participação dos alunos nas decisões sobre a prática didática em sala de aula, as respostas foram negativas com a justificativa de que há muito desrespeito por parte dos alunos. 
Para os diretores da escola, as questões foram mais relacionadas ao seu papel como profissionais no processo de ensino-aprendizagem, com respostas convergindo para a importância do bom relacionamento entre eles, os professores e os alunos, o que, na escola particular, é levado em conta no momento da contratação do professor. Da mesma forma, os diretores ressaltaram a importância de escolher metodologias "diferenciadas", para que o conteúdo "faça sentido" para os alunos, com destaque às que valorizem o entendimento prático de conceitos como porcentagem e assuntos financeiros, com o objetivo de fazer os alunos refletirem sobre conceitos mais amplos, como "justiça".

A partir de todas essas informações, Herminio (2008) desenvolveu seu projeto de ensino de Matemática Financeira no Ensino Médio com os seguintes tópicos: noção de Porcentagem; conceitos de Capital, Juros, Taxa de Juros, Unidade de Tempo, Prazo e Montante; Juros Simples e Juros Compostos; e Parcelamento.

Após a aplicação do projeto, Herminio (2008) conclui, a partir de relatos dos próprios alunos, que estes "puderam se sentir mais orientados", no sentido de construir seus conhecimentos futuros relacionados ao uso dos conceitos de Matemática Financeira e que isso foi resultado do aproveitamento de situações reais no projeto. Dessa forma, para Herminio (2008), "o ideal seria que houvesse, no programa escolar, um tempo dedicado exclusivamente para um trabalho com Matemática Financeira e com um enfoque no social".

\section{Educação para a vida: perspectiva conceitual e instrumental}

Com uma proposta parecida com as duas anteriores, a análise da dissertação de Souza (2016) se baseia no princípio de que o ensino escolar deve buscar um equilíbrio entre o aprendizado conceitual, que é abstrato e distante da realidade, e instrumental, que é concreto e contextualizado. Para Souza (2016), esse equilíbrio é necessário para o que ela chama de "Educação para a Vida".

Também adotando a metodologia de Resolução de Problemas, Souza (2016) preparou cinco atividades para serem trabalhadas por 89 alunos de três turmas do 9o ano do Ensino Fundamental de uma escola pública de Curitiba (PR). Souza (2016) explica que, como professora da disciplina, sempre esteve inquieta para entender por que os alunos estão tão desinteressados em aprender Matemática, o que a levou a redirecionar sua prática pedagógica, de modo a utilizar a Matemática Financeira como "pano de fundo".

Assim, de acordo com Souza (2016), a afetividade define o que é significativo para a perspectiva e o planejamento de vida de cada um, de modo que uma educação financeira "para a vida" possibilita seguir um planejamento construído por interesses, condições e aptidões individuais e coletivos, de acordo com a ideia de "cidadania crítica".

Segundo Souza (2016), o método de ensino baseado na resolução de problemas propicia a autonomia do aluno e desenvolve seu senso crítico, o que o instiga a observar, além dos limites da escola, situações do seu cotidiano com postura ativa e questionadora, o que, no caso da Matemática Financeira, se concretiza em suas escolhas em relação a gastos e consumo, por exemplo, mas sem ser "domesticado" para agir estritamente de acordo com um modelo pronto. 
Diante da leitura das atividades realizadas pelos alunos para responder, Souza (2016) conclui que a Educação Financeira pode integrar a Matemática curricular no Ensino Fundamental, de modo a possibilitar que os alunos construam bases para o futuro ao mesmo tempo em que compreendem a perspectiva conceitual do ensino, fazendo uma ligação entre a sala de aula e a vida cotidiana.

\section{RESULTADOS E DISCUSSÃO}

Para a apresentação da proposta de ensino de Matemática Financeira nas escolas de Ensino Médio, é tomado como base o assunto referente à Matemática Financeira básica presente em Santos (2018). Nesse sentido, a matéria está dividida em cinco aulas: Fundamentos da Matemática Financeira; Juros Simples; Desconto Simples; Juros Compostos; e Sistemas de Amortização.

$\mathrm{Na}$ aula 01, a ideia é fazer os alunos refletirem sobre capital e juros a partir do que eles já sabem, antes de esses conceitos serem explicados pelo professor. Dessa forma, o professor apenas registraria no quadro palavras-chave presentes nas respostas, sem corrigi-las, para, em seguida, apresentar uma definição mais rigorosa e demonstrar como, eventualmente, muitas das respostas se aproximaram dela.

$\mathrm{Na}$ aula 02, antes de entrar na fórmula de juros simples, é necessário que o professor retome a ideia de taxa de juros para trabalhar com o entendimento do período de pagamento, isto é, ano, mês, dia, etc. O que deve ser enfatizado é que uma mesma taxa de juros assume valores diferentes em diferentes períodos estipulados para o pagamento, de forma que a quantia paga a título de juros também será diferente. Ao entender que as taxas são equivalentes, mas os juros pagos não, o entendimento do juro como consequência da "preferência temporal", expressa numericamente na taxa de juros, está completo.

Assim, na aula 03, o conhecimento de juros simples poderá ser expandido para situações mais familiares ao cotidiano dos alunos, como os descontos oferecidos em lojas, nas modalidades "racional" e "comercial". Para isso, o professor poderá perguntar aos alunos as modalidades de desconto que conhecem e o porquê de algum vendedor oferecer descontos de acordo com o prazo de pagamento. $\mathrm{O}$ objetivo é que o aluno entenda que a ideia de desconto, no contexto de pagamento à vista ou antecipado, é simplesmente o inverso da de juros.

Na aula 04, o professor trabalhará com juros compostos, o que já está previsto no quadro de habilidades da BNCC, mas, nesta proposta, será abordada com maior estímulo à participação e à contextualização por parte dos alunos, utilizando o exemplo da Caderneta de Poupança, que a maioria dos alunos conhece. Finalmente, na aula 05, o professor deverá questionar aos alunos sobre o realismo dos exercícios de aulas anteriores, em que alguém paga um produto comprado a prazo em apenas uma parcela após a carência. Espera-se que os alunos estejam familiarizados com a prática de pagar "prestações".

Nesse cenário, os alunos podem perceber que cada parcela inclui a "amortização", isto é, o pagamento de parte do valor à vista, e os juros. Antes de mostrar as formas de cálculo, no entanto, o professor deve conceituar e contextualizar os dois sistemas de amortização mais comuns: Sistema de Amortização Constante (SAC) e Sistema Price. 
Para avaliar a viabilidade dessa proposta de ensino pela ótica dos professores, foi aplicado um questionário a 28 professores de diversas regiões do país. $\mathrm{Na}$ questão "Você considera que os alunos têm interesse em aprender Matemática Financeira? Por quê?" foram obtidas 26 respostas, com metade manifestando ausência ou insuficiência de interesse. Dentre essas respostas negativas, destacam-se estas três: "A dificuldade que eles têm desperta um desinteresse"; "Eles apresentam muitas dificuldades com cálculos"; "O ensino de Matemática Financeira é colocado como um adendo de Progressões, diminuindo o conteúdo e sua importância para o aluno".

Entre as respostas afirmativas, destacam-se outras três: "Um interesse ligeiramente superior à média por se tratar de uma situação aplicável no dia a dia"; "Eles observam que é um estudo importante para a educação financeira"; "Se não for só a apresentação de fórmulas prontas e aplicação, o conteúdo pode ser interessante".

Na questão "Você considera que o ensino de Matemática Financeira é importante para o exercício crítico da cidadania dos indivíduos? Por quê?", foram obtidas 27 respostas, sendo apenas duas negativas. Dentre as respostas positivas, destacam-se estas três: "A situação social de hoje é reflexo do modelo educacional de ontem"; "A matemática financeira do Ensino Médio tem um grande potencial o desenvolvimento de cidadãos mais comprometidos com seu entorno"; "Hoje em dia, todos lidamos com matemática financeira, não são todos que compram tudo à vista e aí está o mais importante, saber o que está se pagando".

Nas respostas negativas, as explicações foram: "Os dados podem ser pesquisados junto a instituições financeiras. Seria melhor trabalhar o orçamento doméstico"; e "Matemática financeira trabalha a parte matemática da educação financeira. Deveria haver aulas de conceitos financeiros, mas não só matemáticos".

Sobre a forma com que essas aulas poderiam ser encaixadas nas limitações de tempo verificadas na realidade das escolas, foi feita a seguinte pergunta: "Você acredita que os alunos poderiam aceitar aprender alguns conceitos de Matemática Financeira que não sejam cobrados em prova, podendo até ser ensinados em aulas extras? Por quê?".

Das 27 respostas obtidas, apenas quatro foram negativas. Dentre as afirmativas, que também enfatizaram mais a aplicação ao dia a dia, e os problemas domésticos, destacam-se estas três: "A escola pode oferecer créditos de atividades extras, com aulas mais 'temáticas' e 'interativas'”; "É uma ótima iniciativa. Devese aplicar tudo que está sendo ensinado ao cotidiano do aluno"; "Os alunos que se interessam por investimentos e mercado financeiro formariam turmas extras com toda a certeza".

Nas respostas negativas, observam-se motivações distintas, como metodologia de ensino particular do professor e o desinteresse e as dificuldades dos alunos em Matemática. Destacam-se três destas quatro respostas: "A grande maioria expressa claramente falta de interesse em matemática"; "Eles querem aprender o mínimo possível para a aprovação"; "Sou contra aulas extras. Deveria existir uma disciplina de educação financeira".

Como síntese geral do questionário, observa-se uma impressão positiva dos professores em relação a uma proposta de ensino do tipo apresentado neste tópico. Mesmo as poucas respostas negativas não discordam da importância de 
uma discussão sobre economia e finanças na escola, ainda que não necessariamente na forma de Matemática Financeira ou com uma profundidade que necessite de aulas extras.

Após essas cinco aulas mais básicas, o professor pode expandir a percepção dos alunos sobre a aplicabilidade dos alunos sobre a Matemática Financeira com o ensino dos princípios sobre os quais opera o Mercado Financeiro, ainda conhecido por muitos como algo distante e restrito a quem tem muito dinheiro, o que, a partir dos conhecimentos de juros compostos, pode ser facilmente desmistificado. Para isso, os tópicos abordados nessa aula são Renda Fixa e Renda Variável, conforme apresentados por Franco e Pardo (2018).

O professor pode conduzir a explicação das aplicações de Renda Fixa com a ideia de que, em vez de alguém tomar empréstimo do banco, é o banco que toma empréstimo dos indivíduos, com uma promessa de pagamento após um período pré-determinado com uma condição de taxa de juros também pré-determinada.

Com esse conhecimento, os alunos podem resolver diversos exercícios envolvendo os conhecimentos de juros compostos aplicado a investimentos de Renda Fixa, comparando rendimento real, em que há o desconto de algum índice de preços e do imposto de renda, com o nominal, que é calculado pela aplicação direta da fórmula dos juros compostos. No caso da Renda Variável, o próprio nome diz que o rendimento pode variar de um período para outro, isto é, não está fixado. Essa variação é determinada pelas ofertas de compra e venda desses ativos, que, tipicamente, correspondem a ações de empresas.

A partir disso, os alunos poderão visualizar que, de acordo com as projeções dos resultados financeiros da empresa em questão, o valor das ações pode subir ou descer, de modo que os investidores podem "especular" o que vai acontecer para decidir se compram ou vendem ações daquela empresa, o que é mais arriscado. Dessa forma, espera-se que os alunos percebam a lógica de que quanto maior for o ganho máximo de um investimento, maior também tenderá a ser seu risco e vice-versa, já que ninguém arriscaria seu dinheiro em algo que não ofereceria uma possibilidade maior de ganho.

Sobre esse assunto, foi feita mais uma pergunta aos mesmos 28 professores que responderam as questões retratadas no subtópico anterior: "Você acha que o aprendizado de conceitos como investimentos de Renda Fixa e Renda Variável seria proveitoso para os alunos aplicarem juros compostos e outros assuntos de Matemática Financeira na escola? Por quê?".

Das 25 respostas obtidas, apenas duas foram negativas ou céticas quanto ao proveito que esses conceitos teriam para os alunos de Ensino Médio. Destacamse, entre as respostas afirmativas, três sendo elas: "Correr riscos pode ser válido, mas um agente racional deve saber quantificá-lo em primeiro lugar"; "Tudo isso está muito presente na nossa vida"; "Os alunos poderiam fazer projeções futuras de rentabilidade e fazer comparações utilizando outros conceitos matemáticos como funções e tipos de gráficos".

Em contraste, verificam-se duas respostas negativas: "Diante do cenário atual, parece longe da realidade, apesar da ideia ser bastante interessante"; "É complicado, pois o aluno precisa de conceitos que ainda não tem". 
Portanto, ainda que haja falhas na aquisição dos pré-requisitos esperados para alunos de ensino médio, a implementação da metodologia descrita e ilustrada neste subtópico e no anterior tem como meta o nivelamento da turma em relação aos conceitos básicos, para que cada aluno possa adquirir sua própria motivação para aprender e aplicar os conhecimentos transmitidos.

\section{CONCLUSÃO}

Nesta pesquisa, optou-se por construir uma proposta de ensino considerada inovadora, embora claramente inspirada nos três estudos de caso relatados e na metodologia explicitada. Assim, a busca por definições mais rigorosas para conceitos que os alunos dominam de forma intuitiva visa valorizar esse saber tácito e propor que ele seja trabalhado, questionado e debatido, antes mesmo de ser aplicado a situações concretas com números e fórmulas.

Nesse particular, a escolha pelo livro de Mises (2004) como principal fonte de consulta se justifica pelo fato de o autor ter construído, com ótima didática, uma obra completa sobre os conceitos abstratos que norteiam a ciência econômica e, consequentemente, sustentam as ideias discutidas nas aulas de Matemática Financeira.

Como a primeira edição desse livro foi publicada em 1949, o professor poderá buscar outras fontes mais atuais para apresentar aos alunos, mas, no entendimento deste trabalho, o livro de Mises (2004) cumpre satisfatoriamente o papel de reforçar a parte introdutória das aulas de Matemática Financeira.

As propostas mais específicas das cinco aulas de Matemática Financeira e mais uma aula de Mercado Financeiro podem necessitar de uma transição para serem viabilizadas. Por isso, foi feita, no questionário entregue aos professores, a pergunta sobre possibilidade de aulas extras. Ainda que correndo o risco de serem desprezadas pelos alunos, essas aulas poderiam lhes passar a mensagem de que 0 conteúdo apresentado na escola não se justifica apenas por ser cobrado em prova.

Nesse sentido, a opção da pesquisadora do Projeto Cálculo, relatado nos estudos de caso, de encaixar as aulas de Matemática Financeira como um conteúdo extra, com abordagem diferenciada, mas ainda sujeito a avaliações individuais por escrito e sem consulta, como são feitas as provas tradicionais, combinado com atividades em grupo, parece ser o passo mais indicado para a transição. 


\title{
Contextualization of financial mathematics with financial market notions: a critical and active teaching proposal in high school
}

\begin{abstract}
The teaching of Financial Mathematics in high school represents a great opportunity to use the subject of Mathematics in a less expository and with a more critical and reflective attitude of the students, in order to build useful knowledge for the exercise of their citizenship. In this work, the critical teaching proposal from the resolution of problems is complemented by the application of simple and compound interest knowledge to the understanding of Fixed and Variable Income applications, in addition to the practical demonstrations of the use of the Price and SAC amortization systems. Thus, based also on different references on the theme, one can realize that, in addition to acting as an instrument of contextualization for different everyday situations, Financial Mathematics can be a transforming tool through the students' experience in Mathematics. The research carried out is anchored in analysis of articles who report classes in which was adopted the Method Based Learning Problem Solving (ABRP), which can stimulate reasoning and students' intuition, and develop a lesson proposal that assimilates the reported strengths, to then submit this proposal for evaluation of Mathematics teachers. As a result, it was noticed that most of the teachers who participated in the evaluation approved the lesson suggested in this paper, but many of them found it difficult to implement the idea and to convince the students of the importance of the topic. As a conclusion, it was noted that the suggested classes should be adapted to the students' assessed abilities and to their interest in learning an extra content that requires more participation.
\end{abstract}

KEYWORDS: Financial Mathematics. ABRP. Financial Market. 


\section{REFERÊNCIAS}

ALMEIDA, A. C. et al. Trabalhando matemática financeira em uma sala de aula do ensino médio da escola pública. 2004. Dissertação (Mestrado em Matemática). Faculdade De Educação - Universidade Estadual De Campinas, Campinas, 2004.

DUCH, B. J. Problem-Based Learning in Physics: The Power of Students Teaching Students. Journal of College Science Teaching, v. 15, n. 5, p. 326-29, 1996.

FRANCO, J.; PARDO, P. Mercado Financeiro e de Capitais. Unicesumar, 2018.

HERMINIO, P. H. Matemática financeira: um enfoque da resolução de problemas como metodologia de ensino e aprendizagem. 2008. Dissertação (Mestrado em Educação Matemática). Instituto de Geociências e Ciências Exatas - Universidade Estadual Paulista, Rio Claro, 2008.

MARGETSON, D. Why problem-based learning is a challenge?. In: BOUD, D.\& FELETTI, G. (Eds). The challenge of problem-based learning. 1. ed. Londres: Kogan Page, 1991. p. 36-44.

MINISTÉRIO DA EDUCAÇÃO. Base Nacional Curricular Comum para o Ensino Médio. 2018a. Disponível em: http://basenacionalcomum.mec.gov.br/wpcontent/uploads/2018/04/BNCC_EnsinoMedio_embaixa_site.pdf. Acesso em: 20 dez. 2018.

MISES, L. Human action. Ludwig von Mises Institute: Auburn, 2004.

ROBBINS, L. An essay on the nature and significance of economic science. Londres: Macmilan, 1932.

SANTOS. D. E. Matemática Financeira. Unicesumar, 2018.

SOUZA, C. C. Z. O ensino da matemática financeira na escola numa perspectiva de educação para vida. 2016. Dissertação (Programa de Mestrado em Educação). Setor de Educação - Universidade Federal Do Paraná, 2016. 


\section{APÊNDICE: Respostas ao questionário}

1) Você acha que o aprendizado de conceitos como investimentos de Renda Fixa e Renda Variável seria proveitoso para os alunos aplicarem juros compostos e outros assuntos de Matemática Financeira na escola? Por quê?

"Sim.";

"Sim, pois os nossos alunos gostam de descobrir o novo, o diferente.";

"Sim, pois é algo usado constantemente por eles.";

"Acredito que sim, pois são conceitos que podem levar para suas vidas, e a escola precisa preparar para a vida e não para avaliações apenas.";

"Sim. Exemplos diários podem ser apresentados.";

"Apenas uma pequena parcela. A grande maioria expressa claramente falta de interesse em matemática.";

"Sim, principalmente a história da matemática financeira e o sistema de amortização americano que não consta nos currículos das escolas públicas.";

"Acredito que não, pois os alunos estão cada vez mais fazendo em aula o que é estritamente necessário para aprovação.";

"A Matemática Financeira deveria ser ensinada em todos os níveis de ensino não se limitando apenas a juros. Existem alguns alunos que se interessam por investimentos e mercado financeiro estes formariam turmas extras com toda certeza.";

"Sim. Tudo depende da maneira que será apresentado, favorecendo a curiosidade de cada um, para tratar de seu dinheiro da maneira que renda mais e com maior segurança.";

"Sim.";

"Sim. Para ter êxito será preciso antes fazer um trabalho de motivação e conscientização. Mostrar ao aluno a importância de saber o quanto está pagando, o valor do consumo consciente, as armadilhas do mercado financeiro.";

"Poucos. Por causa das dificuldades básicas, acabam não se interessando e não percebendo a importância desses conceitos.";

"Sim, desde que o projeto fosse bem estruturado e com apoio de coordenadores e gestores escolares.";

"A matématica financeira está no cotidiano e poderia ser abordada em aulas extras sim, como aprender a investir no tesouro por exemplo.";

"Sou contra aulas extras. Devia existir uma disciplina de educação financeira."; 
"Depende de como for introduzida a presença deles. Pode sim ser ensinado em horário extra.";

"O conceito de amortização.";

"Sim. Desde que sejam atrativos e façam parte de seu contexto.";

Sim, com as devidas orientações e esclarecimentos sobre o conteúdo.";

"Acredito que sim, seria muito positivo aprenderem não somente aquilo que vem sendo mostrado nos livros, com fórmulas prontas, etc, mas o seu uso no cotidiano e obtenção de novos conhecimentos.";

"Sim, desde que a escola ofereça créditos de atividades extras, dentre as quais os alunos são obrigados a escolher algumas, e que a aula não envolva a execução de muitos exercícios ou de exercícios muito difíceis, sendo mais "temática" e interativa.";

"Acho que não, aparentemente eles querem aprender o mínimo possível para a aprovação.";

"Sim. Quando trabalho matemática financeira, observo que os alunos querem entender sempre mais.";

"Creio que sim [...] tal assunto (em alguns) proporciona um bom uso de tecnologia atrelado ao capital.";

"Sim, conhecer um pouco a mais de matemática financeira assim como o mercado financeiro é uma ótima iniciativa. Como por exemplo mostrar para o aluno porque tesouro direto é melhor que poupança, mostrando porque um rende mais que o outro. Deve-se aplicar tudo que está sendo ensinado, para o cotidiano do aluno."

2) Você acha que o aprendizado de conceitos como investimentos de Renda Fixa e Renda Variável seria proveitoso para os alunos aplicarem juros compostos e outros assuntos de Matemática Financeira na escola? Por quê?

"Sim.";

"Sim, Sem dúvidas, pois tudo isso está muito presente na nossa vida, como financiamentos de carros e casa, empréstimos em bancos ou de terceiros, compras em lojas a vista, no crediário ou com cartão, quando fazemos aplicações em banco como, por exemplo, a poupança entre outras situações que ocorre em nosso cotidiano.";

"Seria muito proveitoso. É importantíssimo conhecer o mercado de investimentos, podendo distinguir propostas que visem lucro, ao invés de prejuízos monetários.";

"Sim, para entenderem como pessoas ganham dinheiro e a importância de se fazer um devido planejamento financeiro para determinadas situações.";

"No ensino básico e no médio é complicado, pois o aluno precisa de conceitos que ainda não tem."; 
"Diante da realidade atual onde alunos do último ano do ensino médio apresentam dificuldade até mesmo com equações simples, até mesmo a tabuada me parece longe da realidade, apesar da ideia ser bastante interessante.";

"Sim, o não conhecimento destes assuntos pode levar os alunos a se desinteressar pelo assunto, quanto a aplicação em fundos de investimento acredito que primeiro tem que aprender educação financeira.";

"Sim. Para uso na vida adulta.";

"Sim. Porque poderiam fazer projeções futuras de rentabilidade e fazer comparações utilizando outros conceitos matemáticos como funções e tipos de gráficos.";

"Sim, por serem as aplicações mais conhecidas além da poupança.";

"Sim. Na realidade todo custo financeiro, tanto na aplicação como no pagamento se baseia no juro composto. Na realidade não há juro simples quando a transação passa de um mês.";

"Sim. Uma forma de manter sua saúde financeira entendendo como funciona o mercado e até evitando cair em armadilhas. E, conhecer outras opções de investimento que não seja só a poupança.";

"Super importante!";

"O conteúdo de juros é muito básico. E toda a parte de aplicação financeira deve ser discutida já com esse conteúdo trabalhado";

"Muito proveitoso. Se queremos que sejam independentes devem aprender assuntos relacionados à finança em geral.";

"É bom falar sobre as possibilidades de investimento. Pois todas as simulações estão disponíveis em sites de busca.";

"Sim. Pois podem precisar saber desses conceitos no futuro.";

"Sim.";

"Acredito que sim. Teria a seu favor conhecimento para seu uso no dia a dia.";

"Sim, pois isso tem a ver com a relação entre taxa de retorno e risco do investimento. Correr riscos pode ser válido, mas um agente racional deve saber quantificá-lo em primeiro lugar.";

"Seria interessante, mas meio distante da realidade deles.";

"Sim. Qualquer meio que vem a fazer o aluno a pensar e tentar ter uma saúde financeira saudável, é válido.";

"Sem dúvida até mesmo como proposta de financiamento de faculdade.";

"Sim, o aprendizado de como funciona o mercado financeiro é essencial pra o aluno."; 
Você considera o ensino de Matemática Financeira nas escolas: 26 respostas

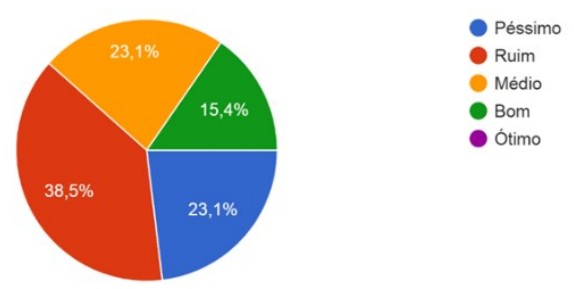

Fonte - Autoria própria (2020).

Gráfico 2 - Conceitos de Matemática Financeira aplicados em sala de aula Quais desses conceitos você já trabalhou em sala de aula? 27 respostas

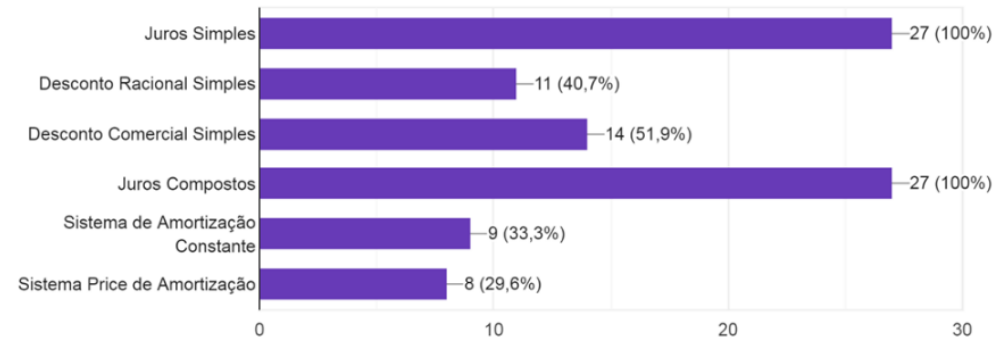

Fonte - Autoria própria (2020).

Gráfico 3 - Conhecimento sobre Mercado Financeiro

Como você considera o seu conhecimento sobre Mercado Financeiro e de Capitais? 27 respostas

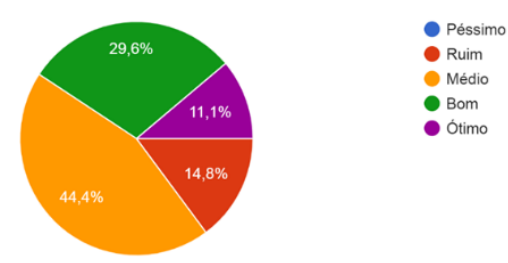

Fonte: Autoria própria (2020). 
Recebido: 30 set. 2019

Aprovado: 24 ago. 2020

DOI: 10.3895/actio.v5n3.10905

Como citar:

ANDRADE III, P. H. de. Contextualização da matéria financeira com noções de mercado financeiro: uma proposta de ensino crítico e ativo no ensino médio. ACTIO, Curitiba, v. 5, n. 3, p. 1-17, set./dez. 2020.

Disponível em: <https://periodicos.utfpr.edu.br/actio>. Acesso em: XXX

Correspondência:

Paulo Hora de Andrade III

Avenida Rio Grande do Sul, n. 2653. Centro. Medianeira, Paraná, Brasil.

Direito autoral: Este artigo está licenciado sob os termos da Licença Creative Commons-Atribuição 4.0

Internacional.

(c) (1) 